\title{
Rigid Water Column Model for Simulating the Emptying Process in a Pipeline Using Pressurized Air
}

\author{
Oscar E. Coronado-Hernández ${ }^{1}$; Vicente S. Fuertes-Miquel' \\ Pedro L. Iglesias-Rey ${ }^{3}$; and Francisco J. Martínez-Solano ${ }^{4}$
}

\begin{abstract}
This paper presents a mathematical model for analyzing the emptying process in a pipeline using pressurized air. The rigid water column model (RWCM) is used to analyze the transient phenomena that occur during the emptying of the pipeline. The air-water interface is also computed in the proposed model. The proposed model is applied along a 271.6-m-long PVC-steel pipeline with a 232-mm internal diameter. The boundary conditions are given by a high-pressure air tank at the upstream end and a manual butterfly valve at the downstream end. The solution was carried out in a computer modeling program. The results show that comparisons between both the computed and measured water flow oscillations and gauge pressures are very similar; hence, the model can effectively simulate the transient flow in this system. In addition, the results indicate that the proposed model can predict both the water flow and gauge pressure better than previous models. DOI: 10.1061/(ASCE)HY.1943-7900.0001446. (c) 2018 American Society of Civil Engineers.
\end{abstract}

Author keywords: Air-water interface; Pipelines emptying; Pressurized air; Transient flow; Water distribution system.

\section{Introduction}

There have been many studies related to behavior during filling and emptying maneuvers in a pipeline, which are typical procedures that engineers have to face in water supply networks. They produce transient phenomena that are complex to analyze considering the particularities of pipeline installations and the nature of the process. The filling procedure can cause pressure surges (Izquierdo et al. 1999); in contrast, the emptying procedure can generate drop in the gauge pressure (Laanearu et al. 2012).

Filling and emptying processes can be analyzed using inertial models: the elastic water model (EWM) and the rigid water column model (RWCM). The EWM considers the elasticity of water and the pipe, while the RWCM ignores them. The solution is obtained using numerical methods (Zhou et al. 2011; Fuertes 2001).

Liou and Hunt (1996) developed a RWCM for analyzing the filling process that only considers the evolution of the water column. Izquierdo et al. (1999) developed a RWCM that considers not only the evolution of the water column but also the air-water

${ }^{1} \mathrm{Ph} . D$. Student, Departamento de Ingeniería Hidráulica y Medio Ambiente, Universitat Politècnica de València, Camino de Vera S/N CP 46022, Valencia, Spain; Assistant Professor, Facultad de Ingeniería, Universidad Tecnológica de Bolívar, Cartagena 131001, Colombia (corresponding author). E-mail: ocoronado@utb.edu.co

${ }^{2}$ Associate Professor, Departamento de Ingeniería Hidráulica y Medio Ambiente, Universitat Politècnica de València, Camino de Vera S/N CP 46022, Valencia, Spain. E-mail: vfuertes@upv.es

${ }^{3}$ Associate Professor, Departamento de Ingeniería Hidráulica y Medio Ambiente, Universitat Politècnica de València, Camino de Vera $\mathrm{S} / \mathrm{N}$ CP 46022, Valencia, Spain. E-mail: piglesia@upv.es

${ }^{4}$ Associate Professor, Departamento de Ingeniería Hidráulica y Medio Ambiente, Universitat Politècnica de València, Camino de Vera S/N CP 46022, Valencia, Spain. E-mail: jmsolano@upv.es

Note. This manuscript was submitted on November 30, 2016; approved on October 18, 2017; published online on February 1, 2018. Discussion period open until July 1, 2018; separate discussions must be submitted for individual papers. This technical note is part of the Journal of Hydraulic Engineering, (C) ASCE, ISSN 0733-9429. interface and the gravity term to represent the irregular profile in the pipeline. Koppel et al. (2010) used the parametric perturbation technique to simulate the filling process in a large-scale pipeline. Zhou et al. (2013b) developed an EWM to analyze a rapid filling process.

The emptying process is the reverse of the filling process in pipelines; however, the emptying process in pipelines has not yet been studied as comprehensively. These studies are very important because pipelines must be emptied periodically. Laanearu et al. (2012) carried out experiments on a PVC-steel pipeline with a 232-mm internal diameter and a 271.6-m length with the primary objective of providing data for future validation. This installation setup consisted of a constant-head water supply tower, a highpressure air tank, a 261-m-long horizontal PVC pipe, a 10.6-mlong steel pipe (divided into a 6.1-m-long horizontal pipe and a 4.5-m-long vertical pipe), PVC and steel joints, steel inlet and outlet parts, various types of valves along the PVC-steel pipeline, and a free-surface basement reservoir. Hydraulic characteristics of the experimental facility have been computed in previous works (Hou et al. 2012; Laanearu and Van't Westende 2010). Tijsseling et al. (2016) and Laanearu et al. (2015) developed a RWCM for analyzing the emptying process using pressurized air. A similar experimental facility was developed by Karadžić et al. (2015).

In this paper, a mathematical model for the emptying procedure in a pipeline using pressurized air is developed based on two physical equations. The first equation is the mass oscillation equation, which provides sufficient accuracy for modeling this phenomenon (Cabrera et al. 1992; Izquierdo et al. 1999; Liou and Hunt 1996). The second equation is the air-water interface equation (Zhou et al. $2013 \mathrm{a}, \mathrm{b})$. The gravity term is added in this model to represent the irregular profile of the pipeline. For validation, the data provided by Laanearu et al. (2012) are used. Comparisons between both the computed and measured water flow oscillations and gauge pressures are conducted along the pipeline. In addition, comparisons between the proposed model and previous models are conducted. Finally, a sensitivity analysis of the height of the vertical pipe is performed. 


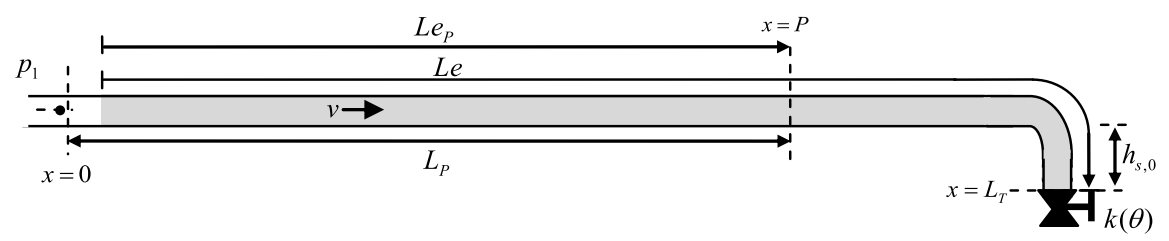

Fig. 1. Pressurized air in a water-emptying horizontal-vertical pipeline

\section{Mathematical Model}

Fig. 1 shows the scheme of the pipeline, which consists of a highpressure air tank, a length of the emptying column, a regulating valve located at the downstream end, a horizontal pipe, and a vertical pipe at the end.

\section{Equations}

The proposed model considers uniform movement within the water column. The following assumptions are made:

- The water behavior is modeled using the rigid model approach;

- The air-water interface has a well-defined cross section; and

- Constant friction accounts for the friction losses.

Based on these assumptions, this problem is modeled using the following equations:

- The mass oscillation equation for an emptying column (rigid water column approach)

$$
\frac{d v}{d t}=\frac{p_{1}}{\rho_{w} L e}+g \frac{h_{s}}{L e}-f \frac{v|v|}{2 D}-k(\theta) \frac{v|v|}{2 L e}
$$

- The interface position of the emptying column

$$
\frac{d L e}{d t}=-v \quad\left(L e=L e_{0}-\int_{0}^{t} v \mathrm{~d} t\right)
$$

where $p_{1}=$ driving gauge pressure; $L e=$ length of the emptying column at time $t ; h_{s, 0}=$ length of the vertical pipe; $v=$ water velocity; $D=$ internal pipe diameter; $k(\theta)=$ minor loss coefficient of the valve; $f=$ pipe wall friction coefficient; $g=$ gravity acceleration; $\rho_{w}=$ water density; $L e_{0}=$ initial length of emptying column at $t=0$; and $h_{s}=$ length of the emptying column at vertical steel pipe.

In summary, a $2 \times 2$ system of differential equations [Eqs. (1) and (2)] describes the whole system. Together with the corresponding boundary and initial conditions, the system of equations can be solved for the two unknowns: $v$ and $L e$.

This process involves the development of a complex model. The solution was calculated using Simulink in MATLAB.

\section{Initial and Boundary Conditions}

The system is assumed to be initially static at $t=0$. Therefore, the initial conditions are described by $v(0)=0, L e(0)=L e_{0}$, and $h_{s}(0)=h_{s, 0}$.

The boundary conditions are as follows:

1. The upstream boundary condition is the manometric pressure $\left(p_{1}\right)$ given by the air tank.

2. The downstream boundary condition is the valve loss described by $k(\theta)$. Water is free to discharge to the atmosphere at $p_{\text {atm }}=0$.

\section{Gravity Term}

The gravity term $\left(h_{s} / L e\right)$ in Eq. (1) depends on the position of the emptying column. For this case, there are two possibilities:

1. When the air-water front of the emptying column has not reached the vertical pipe $\left(L e \geq h_{s, 0}\right)$

$$
\frac{h_{s}}{L e}=\frac{h_{s, 0}}{L e}
$$

2. When the air-water front of the emptying column has reached the vertical pipe $\left(L e<h_{s, 0}\right)$

$$
\frac{h_{s}}{L e}=1
$$

If the configuration setup is different, then the gravity term will be different.

\section{Pressure Inside of Pipeline}

The manometric pressure along the pipeline (at Point $\mathrm{P}$ ) can be computed as follows:

$$
p_{P}=p_{1}-\rho_{w} L e_{P}\left(\frac{f}{2 D} v|v|+\frac{d v}{d t}\right)
$$

where $L e_{P}=$ length of the emptying column until Point $\mathrm{P}$ at time $t$.

To calculate $L e_{P}$, the following expressions can be used:

$$
L e_{P}= \begin{cases}L_{P}-L_{T}+L e, & L_{T}-L e<L e_{P} \\ 0, & L_{T}-L e \geq L e_{P}\end{cases}
$$

where $L_{T}=$ pipe length.

\section{Numerical Model Validation}

The proposed model was applied to conditions based on experiments conducted by Laanearu et al. (2012). Fig. 2 presents a scheme of this installation. For this analysis, an average internal diameter of $232 \mathrm{~mm}$ was used, as suggested by Tijsseling et al. (2016), and therefore the viscosity and surface tension effects in the water-air system are not significant (Laanearu et al. 2012; Liou and Hunt 1996; Pothof and Clemens 2010).

The upstream boundary conditions for the nine runs were provided by the driving air-pressure head values that were based on measurements made by Laanearu et al. (2012), as shown in Fig. 3.

The downstream boundary conditions were provided by both the water freely discharged to the atmosphere $\left(p_{\text {atm }}=0\right)$ and the position of the manual butterfly valve. According to the experiments of Laanearu et al. (2012), the calibrated minor-loss coefficients $k(\theta)$ for the nine runs were $3.32,3.50,3.48,3.64,5.88$, $21.24,3.84,6.14$, and 22.68 . 

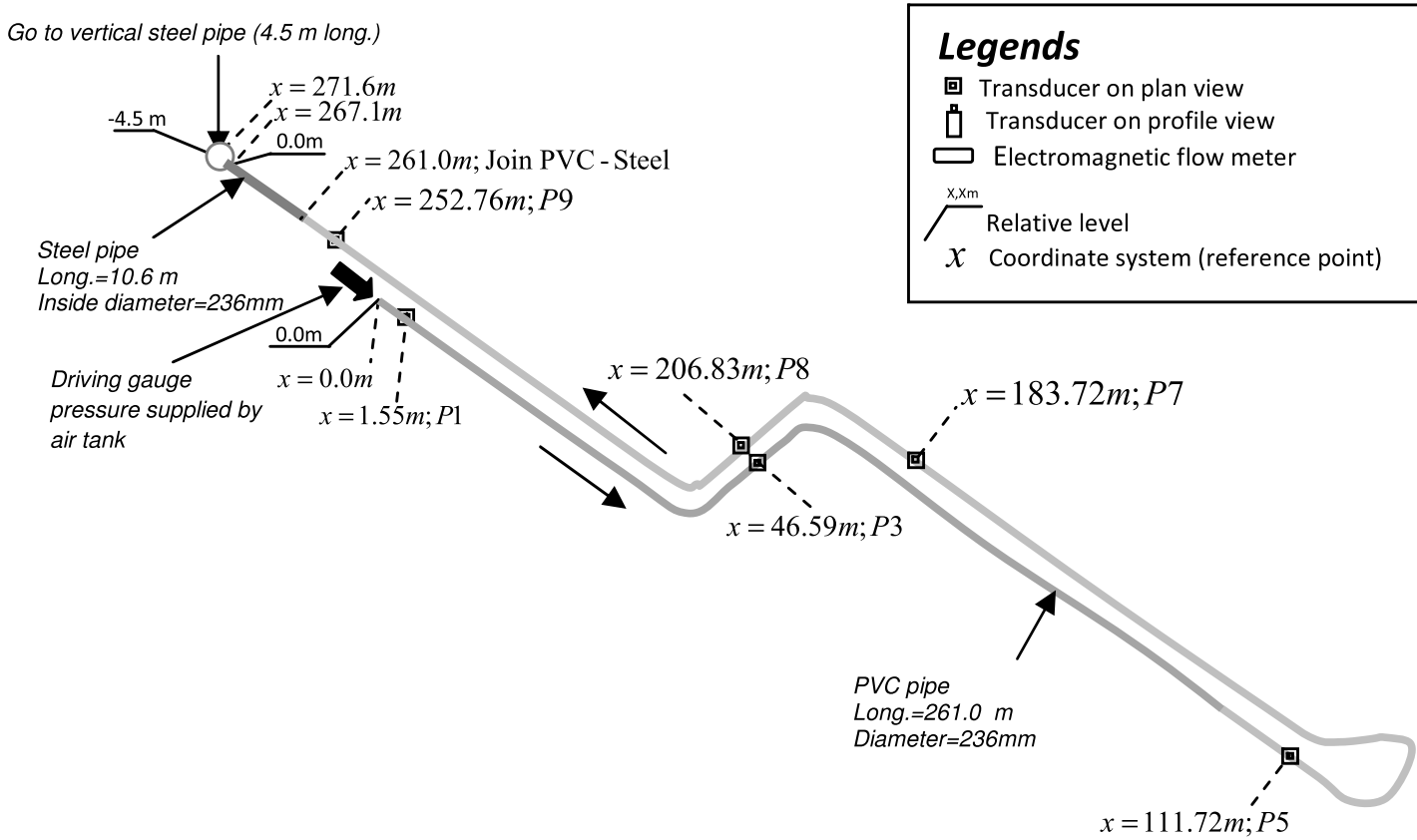

(a)

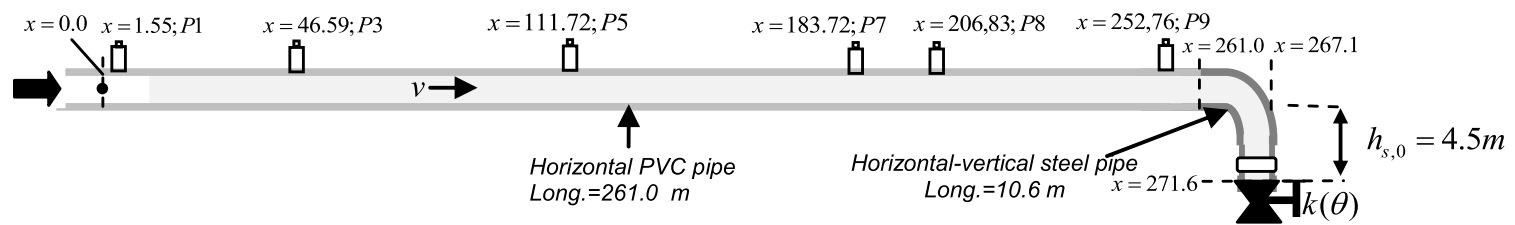

(b)

Fig. 2. PVC-steel pipeline and instrumentation: (a) plan view; (b) profile view along the axis of the pipeline

\section{Proposed Model Verification}

To validate the model, comparisons between both the computed and measured water flow oscillation patterns and gauge pressure patterns were conducted. A friction factor of $f=0.0117$ was selected considering a usual PVC pipe roughness size $(0.0034 \mathrm{~mm})$ and a Reynolds number of 950,000 (Laanearu et al. 2012).

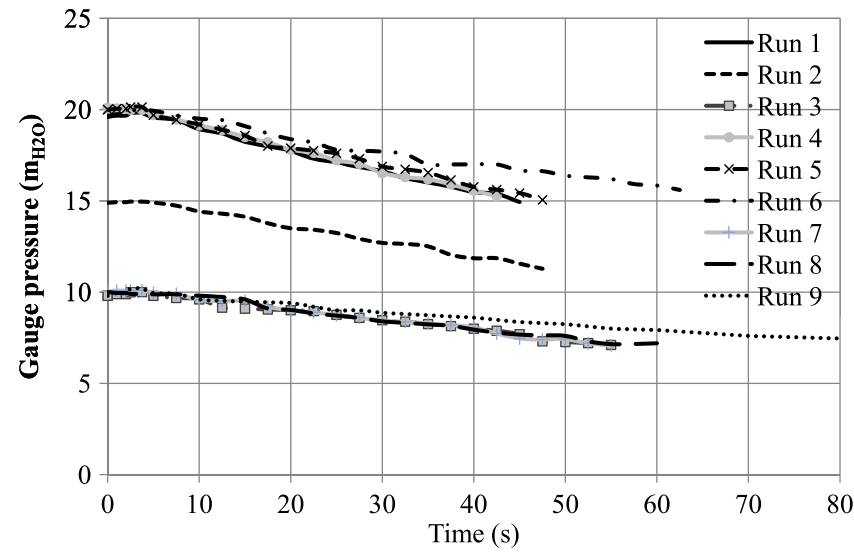

Fig. 3. Gauge pressure supplied by the air tank during the transient stage (data from Laanearu et al. 2012)
The water flow was determined at the downstream end for the nine runs by varying the opening of the manual butterfly valve. Fig. 4 shows a comparison of the computed and measured water flow oscillation patterns for Runs 1, 4, 5, and 9 at the installation. The comparisons indicate that the water flow oscillations from the model are similar to those of the experiments. Consequently, the proposed model can effectively simulate the transient flow during an emptying process using pressurized air in a pipeline. For all runs, few results were affected by varying the opening of the manual butterfly valve.

Table 1 compares all nine runs. For each run, the initial length of the emptying column and the location of the air-water front were considered. Comparisons were made between Sections 1 and 9 located at $x=1.55 \mathrm{~m}$ and $x=252.76 \mathrm{~m}$, respectively. The proposed model shows good overall agreement with the experimental data for water velocities at Section $1\left(v_{1}\right)$ and Section $9\left(v_{9}\right)$. Greater differences are presented in Section 1 for Runs 2 and 3 and in Section 9 for Run 1. The model presents lower values of $\tau_{1-9}$ at these conditions compared with the measured data.

For Run 4 , the evolution of the gauge pressure along the PVCsteel pipeline at Locations P3 $(x=46.59 \mathrm{~m}), \mathrm{P} 5(x=111.72 \mathrm{~m})$, P7 $(x=183.72 \mathrm{~m})$, and P8 $(x=206.83 \mathrm{~m})$ was determined. The proposed model can also approximately reproduce the experimental gauge pressure along the PVC-steel pipeline during the transient phenomenon for Run 4 (Fig. 5). At Locations P3, P5, P7, and $\mathrm{P} 8$, the model excels at predicting the water flow along the PVC-steel pipeline. In all measurements, during the first $15 \mathrm{~s}$, 

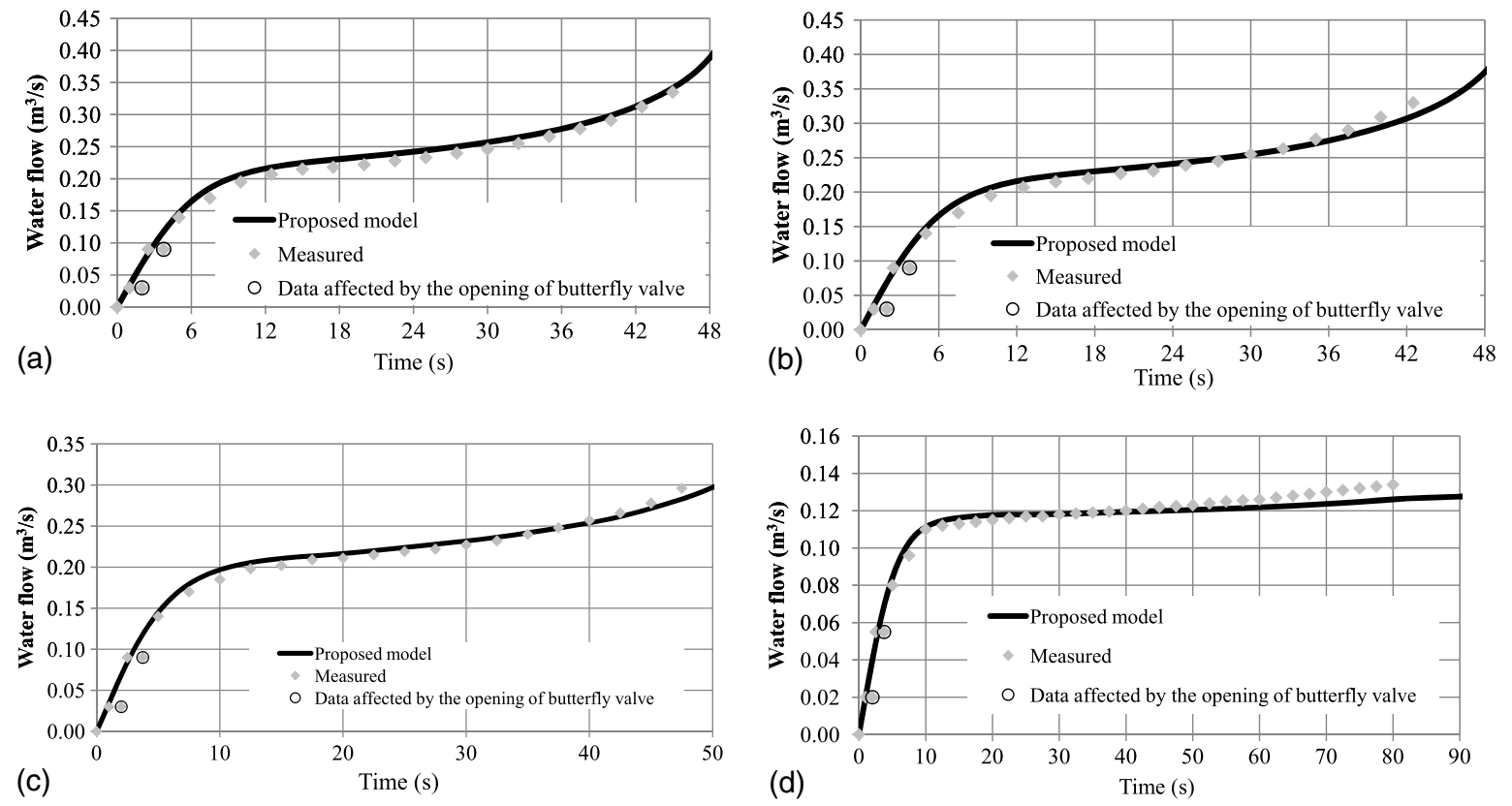

Fig. 4. Comparisons between the calculated and measured water flow oscillation patterns: (a) Run 1; (b) Run 4; (c) Run 5; (d) Run 9

Table 1. Comparison between Computed and Measured Water Velocities and Time When the Air-Water Front Passes by Sections 1 and 9

\begin{tabular}{|c|c|c|c|c|c|c|c|c|c|}
\hline $\begin{array}{l}\text { Run } \\
\text { number }\end{array}$ & $k(\theta)$ & $\begin{array}{l}x_{i, 0}{ }^{\mathrm{a}} \\
(\mathrm{m})\end{array}$ & $\begin{array}{c}L e_{0}{ }^{\mathrm{b}} \\
(\mathrm{m})\end{array}$ & $\begin{array}{c}\text { Measured } \\
v_{1}(\mathrm{~m} / \mathrm{s})\end{array}$ & $\begin{array}{c}\text { Calculated }^{\mathrm{c}} \\
v_{1}(\mathrm{~m} / \mathrm{s})\end{array}$ & $\begin{array}{c}\text { Measured } \\
v_{9}(\mathrm{~m} / \mathrm{s})\end{array}$ & $\begin{array}{c}\text { Calculated }^{\mathrm{c}} \\
v_{9}(\mathrm{~m} / \mathrm{s})\end{array}$ & $\begin{array}{c}\text { Measured } \\
\tau_{1-9}(\mathrm{~s})\end{array}$ & $\begin{array}{c}\text { Calculated }^{\mathrm{c}} \\
\tau_{1-9}(\mathrm{~s}) \\
\end{array}$ \\
\hline 1 & 3.32 & -16.2 & 287.8 & 4.18 & 4.28 & 7.90 & 9.13 & 37 & 40 \\
\hline 2 & 3.50 & -20.8 & 292.4 & 2.83 & 4.03 & 7.04 & 7.98 & 45 & 46 \\
\hline 3 & 3.48 & -20.7 & 292.3 & 2.29 & 3.46 & 6.20 & 6.85 & 51 & 53 \\
\hline 4 & 3.64 & -14.7 & 286.3 & 4.20 & 4.17 & 8.13 & 8.84 & 36 & 41 \\
\hline 5 & 5.88 & -14.7 & 286.3 & 4.07 & 4.07 & 6.91 & 7.34 & 40 & 45 \\
\hline 6 & 21.24 & -13.1 & 284.7 & 3.43 & 3.39 & 4.16 & 4.16 & 54 & 65 \\
\hline 7 & 3.84 & -12.9 & 284.5 & 3.20 & 3.11 & 6.38 & 6.59 & 46 & 54 \\
\hline 8 & 6.14 & -13.8 & 285.4 & 3.09 & 3.07 & 5.42 & 5.53 & 50 & 59 \\
\hline 9 & 22.68 & -15.8 & 287.4 & 2.55 & 2.63 & 3.09 & 3.04 & 69 & 83 \\
\hline
\end{tabular}

Note: $L e_{0}=$ initial length of the emptying column; $v_{1}$ and $v_{9}=$ outflow velocities when the air-water front passes by Sections 1 and 9 , respectively; $x_{i, 0}=$ initial air-water front coordinate; $\tau_{1-9}=$ time between Sections 1 and 9.

${ }^{\mathrm{a} D a t a}$ measured by Laanearu et al. (2012).

${ }^{\mathrm{b}}$ Data computed at $x_{i, 0}+271.6 \mathrm{~m}$.

${ }^{\mathrm{c}}$ Data computed by the current model.

transient oscillations were observed by the gauge pressure readings due to opening the manual butterfly valve. To calculate these oscillations, the opening curve of the ball valve is required. At Locations P3 and P5, the proposed model can properly reproduce the measurements after the oscillations have finished. At Locations P7 and P8, the model can predict the maximum value of the gauge pressure after 1.7 and $2.2 \mathrm{~s}$, respectively. The proposed model can successfully predict the peak pressure, which is very important for ensuring the safety of the pipeline.

\section{Comparisons with a Previous Model}

Tijsseling et al. (2016) developed a model to simulate the emptying process in a pipeline using pressurized air based on the experiments conducted by Laanearu et al. (2012). This model assumed that the velocity of the water column was not uniform because the movements of the front and tail ends were different. As a consequence, the water column is modeled as slug flow, whereas the tail leakage is modeled by introducing a holdup coefficient that relates the ratio between the quantity of the volume occupied by water and air. This model is solved using an analytical solution (Tijsseling et al. 2016).

In this section, a comparison is presented between the proposed model and Tijsseling's model. All the parameters and conditions in the proposed model and the Tijsseling's model were identical.

Fig. 6 presents a comparison of the water flow oscillation for Runs 2 and 6 between the results obtained by the proposed model and Tijsseling's model. In all cases, the proposed model can reproduce the water flow oscillations better than Tijsseling's model. Fig. 6(b) shows that the model developed by Tijsseling et al. (2016) cannot adequately reproduce Run 6 because the water flow oscillation is too low. One explanation could be that the calibration of the holdup coefficient is not appropriate for modeling this run.

Fig. 7 shows a comparison of the gauge pressure along the pipeline for Run 4 at Locations P1 $(x=1.55 \mathrm{~m})$ and P9 $(x=252.76 \mathrm{~m})$. For locations along of the pipe far from the origin coordinate, Tijsseling's model cannot adequately reproduce the 

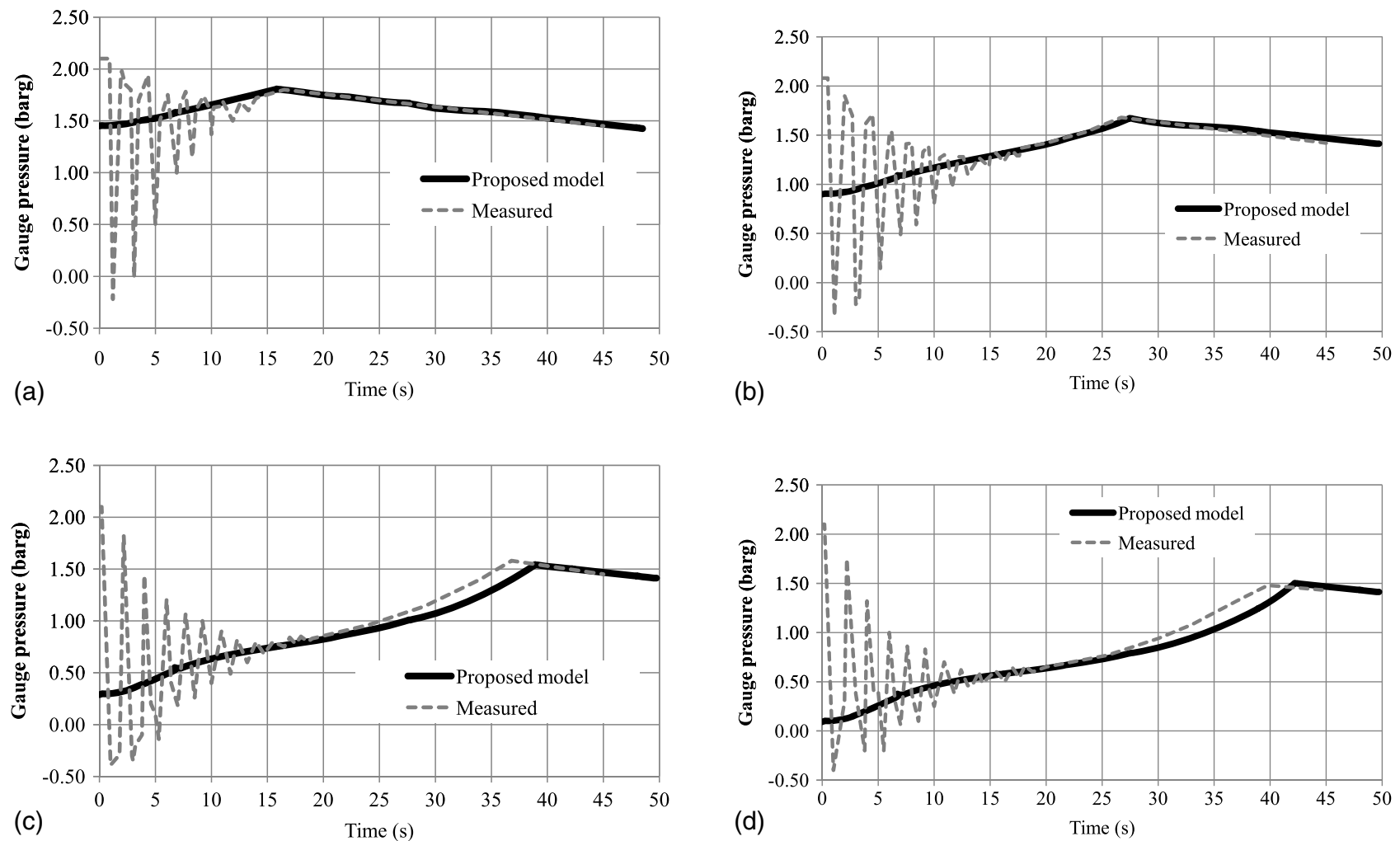

Fig. 5. Comparisons between the calculated and measured gauge pressure oscillation patterns for Run 4: (a) Transducer 3, located at $x=46.59 \mathrm{~m}$; (b) Transducer 5, located at $x=111.72 \mathrm{~m}$; (c) Transducer 7, located at $x=183.72 \mathrm{~m}$; (d) Transducer 8, located at $x=206.83 \mathrm{~m}$
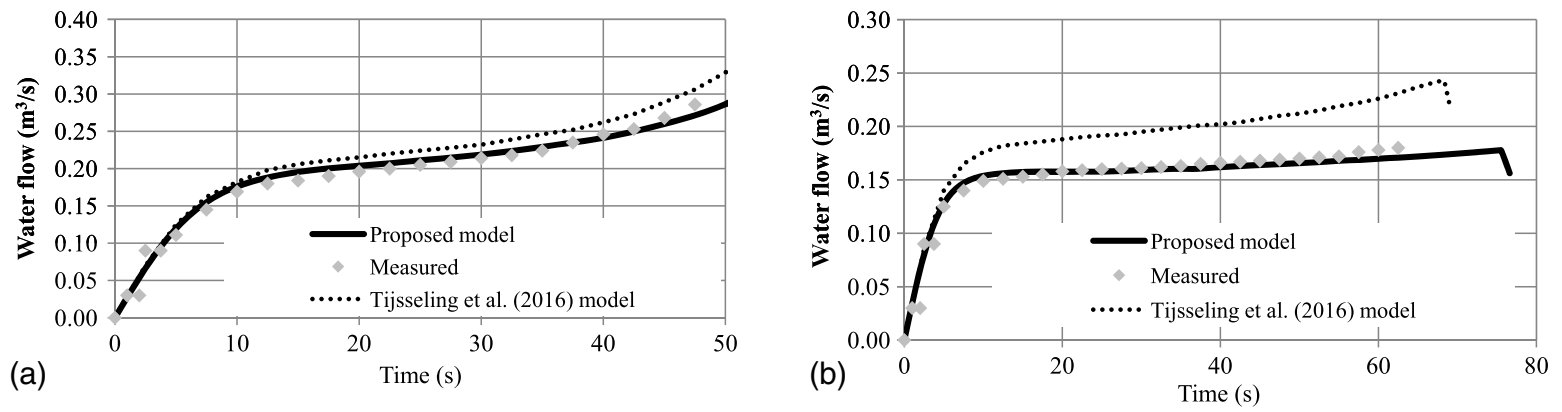

Fig. 6. Comparison of the water flow oscillation pattern: (a) Run 2; (b) Run 6
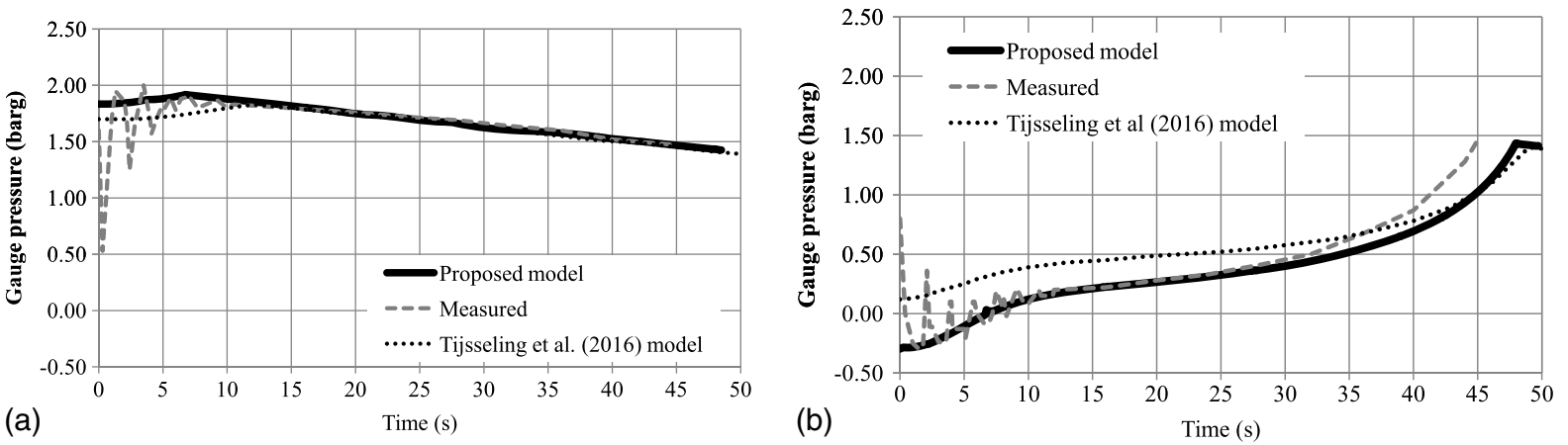

Fig. 7. Comparison of the gauge pressures along the pipeline for Run 4: (a) Transducer 1, located at $x=1.55 \mathrm{~m}$; (b) Transducer 9, located at $x=252.76 \mathrm{~m}$ 


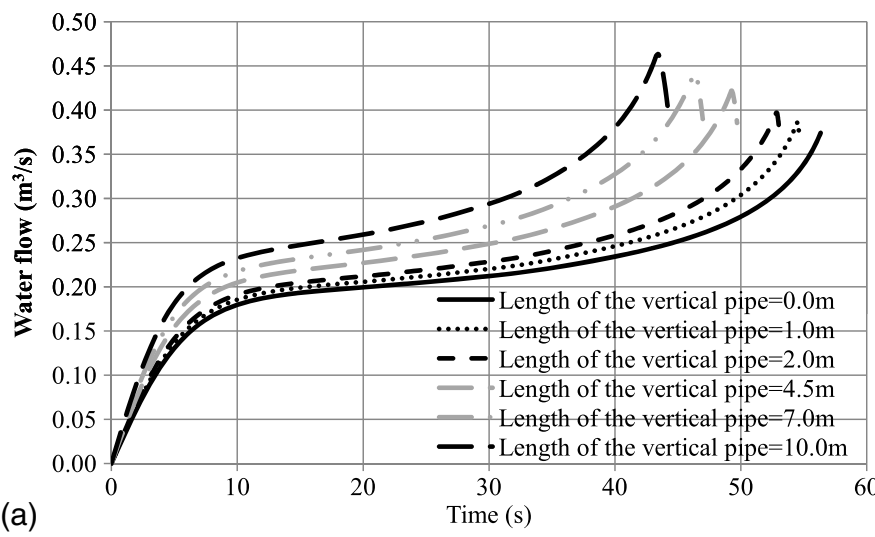

Fig. 8. Effects of the length of the vertical steel pipe: (a) water flow; (b) gauge pressure at Transducer 7 , located at $x=183.72 \mathrm{~m}$ pressure pattern. Again, the proposed model can better predict the gauge pressure oscillations than the model developed by Tijsseling et al. (2016).

\section{Influence of the Length of the Steel Pipe}

It is important to consider the considerable influence of the length of the steel vertical pipe $\left(h_{s, 0}\right)$ on the emptying process; therefore, values of $1.0,2.0,4.5,7.0$, and $10.0 \mathrm{~m}$ were considered to determine the water flow and the gauge pressure variations (Fig. 8). The pipe length $\left(L_{T}\right)$ remained constant in all cases.

Fig. 8(a) presents the influence of the vertical steel pipe length on the water flow. The longer the length of the vertical pipe $\left(h_{s, 0}\right)$, the faster the draining process occurs because the gravity term is increased. In this case, the emptying times range between 56.3 and $44.3 \mathrm{~s}$. In addition, the higher the length of vertical pipe, the higher the water flows during the transient stage; the maximum values are between 0.37 and $0.46 \mathrm{~m}^{3} / \mathrm{s}$. At the end of the transient stage, the water flow has a rapidly decreasing linear profile inside the vertical pipe. When $h_{s, 0}=0$, the installation does not have this tendency.

Fig. 8(b) shows the influence of the length of the vertical steel pipe on the gauge pressure at Transducer P7. The maximum gauge pressures increase with increasing length of the vertical pipe steel along the pipeline, with gauge pressure values between 149 and $159 \mathrm{kPa}$ (1.49 and $1.59 \mathrm{barg}$ ). In addition, higher vertical steel pipe lengths cause higher minimum gauge pressures along the pipeline, which occur at the beginning of the transient stage. At Transducer $\mathrm{P} 7$, the highest minimum gauge pressure is $-3 \mathrm{kPa}(-0.03 \mathrm{barg})$. The minimum gauge pressure occurs at the upstream end. The minimum and maximum gauge pressures occur simultaneously during the transient stage. When the air-water front reaches a particular point during the transient stage, the gauge pressure is the driving gauge pressure.

\section{Conclusions}

A mathematical model for accurately determining the emptying operation in a pipeline using pressurized air was developed in this paper. It can be used for several pipeline configurations by changing only the gravity term.

The mathematical model was validated using data recorded by Laanearu et al. (2012) for a PVC-steel pipeline that was $271.6 \mathrm{~m}$ long with a 232-mm internal diameter. The model effectively simulated measurements of the transient water flow and gauge pressure along the pipeline for nine runs.

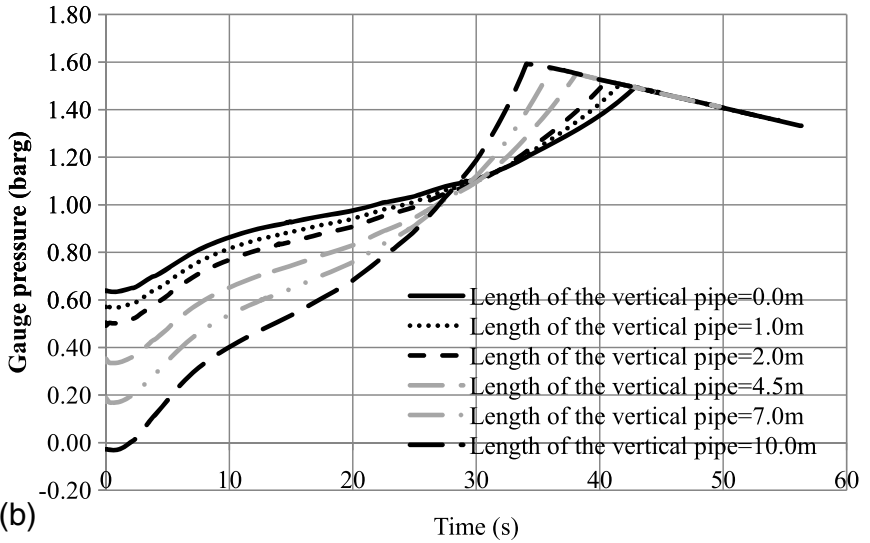
emptying process can better predict both the water flow and gauge pressure along a pipeline than previous models.

The length of the vertical pipe significantly influences the results. The time for drainage decreases as the vertical steel pipe length increases, possibly because the water flow increases. However, it should be considered that the maximum and minimum gauge pressures will also increase, putting the system at risk. Considering this, it is recommended to select a suitable length for the vertical steel pipe to reduce the probability of system failure.

Real systems will present greater challenges, for instance, pipelines with irregular profile having high points that require the operation of vacuum valves.

\section{Acknowledgments}

Funding for Oscar E. Coronado-Hernández (doctoral student) was covered by Fundación Centro de Estudios Interdisciplinarios Básicos y Aplicados (CEIBA)-Gobernación de Bolívar (Colombia).

\section{Notation}

The following symbols are used in this paper:

$D=$ internal pipe diameter $(\mathrm{m})$;

$f=$ pipe wall friction coefficient;

$g=$ gravity acceleration $\left(\mathrm{m} / \mathrm{s}^{2}\right)$;

$h_{s}=$ length of the emptying column at the vertical pipe (m);

$h_{s, 0}=$ height of the vertical pipe $(\mathrm{m})$;

$k(\theta)=$ minor-loss coefficient;

$L e=$ length of the emptying column (m);

$L e_{0}=$ initial length of the emptying column (m);

$L e_{P}=$ length of the emptying column until Point P (m);

$L_{T}=$ pipe length (m);

$p_{1}=$ driving gauge pressure $(\mathrm{Pa})$;

$p_{\text {atm }}=$ atmospheric pressure $(\mathrm{Pa})$;

$p_{P}=$ gauge pressure at Point $P(\mathrm{~Pa})$;

$t=$ time $(\mathrm{s})$;

$v=$ water velocity $(\mathrm{m} / \mathrm{s})$;

$x=$ axial coordinate $(\mathrm{m})$;

$x_{i, 0}=$ initial air-water front coordinate $(\mathrm{m})$; and

$\rho_{w}=$ water density $\left(\mathrm{kg} / \mathrm{m}^{3}\right)$. 


\section{References}

Cabrera, E., Abreu, J., Pérez, R., and Vela, A. (1992). "Influence of liquid length variation in hydraulic transients." J. Hydraul. Res., 10.1061 /(ASCE)0733-9429(1992)118:12(1639), 1639-1650.

Fuertes, V. S. (2001). "Hydraulic transients with entrapped air pockets." Ph.D. thesis, Polytechnic Univ. of Valencia, València, Spain.

Hou, Q., et al. (2012). "Experimental study of filling and emptying of a large-scale pipeline." CASA-Rep., Technische Universiteit Eindhoven, Eindhoven, Netherlands.

Izquierdo, J., Fuertes, V., Cabrera, E., Iglesias, P., and Garcia-Serra, J. (1999). "Pipeline start-up with entrapped air." J. Hydraul. Res., 37(5), 579-590.

Karadžić, U., Strunjaš, F., Bergant, A., Mavrič, R., and Buckstein, S. (2015). "Developments in pipeline filling and emptying experimentation in a laboratory pipeline apparatus." Proc., 6th IAHR Meeting on WG Cavitation and Dynamic Problems (Ljubljana) (Novo Mesto), International Association for Hydraulic Research, Ljubljana, Slovenia, 273-280.

Koppel, T., Laanearu, J., Annus, I., and Raidmaa, M. (2010). "Using transient flow equations for modelling of filling and emptying of large-scale pipeline." 12th Annual Conf. on Water Distribution Systems Analysis (WDSA), ASCE, Reston, VA, 112-121.

Laanearu, J., et al. (2012). "Emptying of large-scale pipeline by pressurized air." J. Hydraul. Eng., 10.1061/(ASCE)HY.1943-7900.0000631, 1090-1100.
Laanearu, J., Hou, Q., Annus, I., and Tijsseling, A. S. (2015). "Watercolumn mass losses during the emptying of a large-scale pipeline by pressurized air." Proc. Est. Acad. Sci., 64(1), 8.

Laanearu, J., and Van't Westende, J. (2010). "Hydraulic characteristics of test rig used in filling and emptying experiments of large-scale PVC pipeline." Proc., HYDRALAB III Joint User Meeting, Forschungszentrum Küste FZK (Coastal Research Centre FZK), Univ. of Hannover, Hannover, Germany.

Liou, C., and Hunt, W. (1996). "Filling of pipelines with undulating elevation profiles." J. Hydraul. Eng., 10.1061/(ASCE)0733-9429(1996) 122:10(534), 534-539.

MATLAB [Computer software]. MathWorks, Natick, MA.

Pothof, I., and Clemens, F. (2010). "On elongated air pockets in downward sloping pipes.” J. Hydraul. Res., 48(4), 499-503.

Tijsseling, A., Hou, Q., Bozkuş, Z., and Laanearu, J. (2016). "Improved one-dimensional models for rapid emptying and filling of pipelines." J. Pressure Vessel Technol., 138(3), 031301.

Zhou, L., Liu, D., and Karney, B. (2013a). "Investigation of hydraulic transients of two entrapped air pockets in a water pipeline." J. Hydraul. Eng., 10.1061/(ASCE)HY.1943-7900.0000750, 949-959.

Zhou, L., Liu, D., and Karney, B. (2013b). "Phenomenon of white mist in pipelines rapidly filling with water with entrapped air pocket." J. Hydraul. Eng., 10.1061/(ASCE)HY.1943-7900.0000765, 1041-1051.

Zhou, L., Liu, D., and Ou, C. (2011). "Simulation of flow transients in a water filling pipe containing entrapped air pocket with VOF model." Eng. Appl. Comput. Fluid Mech., 5(1), 127-140. 